\title{
Nonlinear and Robust Control Strategy Based on Chemotherapy to Minimize the HIV Concentration in Blood Plasma
}

\author{
Ricardo Aguilar-López, ${ }^{1}$ Rigel Valentín Gómez-Acata, ${ }^{1}$ \\ Gerardo Lara-Cisneros, ${ }^{2}$ and Ricardo Femat ${ }^{3}$ \\ ${ }^{1}$ Department of Biotechnology and Bioengineering, CINVESTAV-IPN, Avenida Instituto Politécnico Nacional 2508, \\ 07360 San Pedro Zacatenco, DF, Mexico \\ ${ }^{2}$ Facultad de Ciencias Química, Universidad Autónoma de San Luis Potosí, Álvaro Obregón No. 64, Colonia Centro, \\ 78000 San Luis Potosí, SLP, Mexico \\ ${ }^{3}$ División de Matemáticas Aplicadas, IPICYT, Camino a la Presa San José 2055, Colonia Lomas 4 Sección, \\ 78216 San Luis Potosí, SLP, Mexico
}

Correspondence should be addressed to Ricardo Aguilar-López; raguilar@cinvestav.mx

Received 23 November 2015; Revised 13 April 2016; Accepted 26 April 2016

Academic Editor: Ai-Guo Wu

Copyright (C) 2016 Ricardo Aguilar-López et al. This is an open access article distributed under the Creative Commons Attribution License, which permits unrestricted use, distribution, and reproduction in any medium, provided the original work is properly cited.

\begin{abstract}
A nonlinear PI-type control strategy is designed in order to minimize the HIV concentration in blood plasma, via medical drug injection, under the framework of bounded uncertain input disturbances. For control design it is considered a simplified mathematical model of the virus infection as a benchmark. The model is based on mass balances of healthy cells, infected cells, and the virus concentrations. The proposed controller contains a nonlinear feedback PI structure of bounded functions of the regulation error. The closed-loop stability of the system is analyzed via Lyapunov technique, in which robustness against system disturbances is demonstrated. Numerical experiments show a satisfactory performance of the proposed methodology as a HIV therapy, in which the virion particles and the infected $\mathrm{CD} 4^{+} \mathrm{T}$ cells are minimized and, as an interesting result, the drug dosage can be suspended, thus avoiding drug resistance from the virus. Finally, the proposed controller is compared to a standard sliding-mode and hyperbolic tangent controllers showing better performance.
\end{abstract}

\section{Introduction}

The Human Immunodeficiency Virus (HIV) causes the named Acquired Immune Deficiency Syndrome (AIDS). This virus is distributed through the mucous membranes and is often transmitted through bodily fluids. It destroys the immune system, by infecting $\mathrm{CD} 4^{+} \mathrm{T}$ cell and the macrophages. Consequently, a poor immune system makes it difficult for the organism to fight against opportunistic infections as pneumonia, meningitis, or tuberculosis causing death. A healthy person has a $\mathrm{CD} 4^{+} \mathrm{T}$ count ranging from 500 to 1000 cells $\mathrm{mm}^{-3}$. A person with a count of 200 cells $\mathrm{mm}^{-3}$ or less of $\mathrm{CD} 4^{+} \mathrm{T}$ is considered to have AIDS. There are rare patients who are infected with HIV, but they are able to suppress the virus without drugs therapy and hence do not develop AIDS; this status is known as long-term nonprogressor (LTNP) $[1,2]$.

The HIV replication cycle can be summarized in six steps: binding and entry; no coating; reverse transcription; provirus integration; virus protein synthesis and assembly; and finally budding [3, 4]. A cure for the HIV infection still has not been found; however since the synthesis of zidovudine (AZT), several drugs have been synthetized belonging to 6 different inhibitor classes approved to fight against the virus and its complications, reducing the viral load. Unfortunately, the synthesis of new drugs is still needed due to the virus drug resistance ability [5]. The drug's target is to prevent the HIV infection in the organism and delay the AIDS, by acting on enzymes and proteins that are vital for the virus to complete its replication cycle and as a result reaching a status in which 
the patient has a sufficient number of $\mathrm{CD} 4^{+} \mathrm{T}$ cells to fight off HIV and other infections, keeping the immune system as healthy as possible. From experience, these drugs alone or in combination are not capable of dropping the viral load to be undetectable for sustained periods of time [5].

One way to analyze the evolution of the HIV dynamic is the mathematic modeling considering the underlying infection mechanisms of the HIV/AIDS to understand and anticipate the spread and evaluate the potential effectiveness of different therapies to bring the infection under control [6]. In keeping with the above, several types of basic modeling approaches have been developed as new information about the HIV pathology and immune system, and therapeutic effects of drugs arise such as the deterministic models, the statistical models, and the stochastic models. In general, they can predict the early phases of disease but cannot predict the decrease in $\mathrm{CD} 4^{+} \mathrm{T}$ cell counts and rise in peripheral virus seen in AIDS $[7,8]$.

Additionally, the HIV mathematical modeling has allowed the analysis of the dynamic behavior of the virus infection, which has helped to propose regulation strategies to diminish indirectly the viral concentration [9-11]. An increasing number of works in the literature deal with the HIV virus regulation via control approaches and reduced HIV models [12-20]. Kim et al. [21] found through a bifurcation analysis the range of optimal constant drug dosing for the reverse transcription inhibitor and the protease inhibitor in order to achieve LTNP in HIV patients. Moreover, by controllability analysis and its singular values, they showed that a therapy with lower/moderate efficacy had a relatively higher efficiency in HIV treatment in terms of controlling the immune system. Barão and Lemos [22] studied the nonlinear control of HIV-1 infection for a three-state model, where the number of healthy and infected $\mathrm{CD} 4^{+} \mathrm{T}$ cells and the number of virion particles are considered; the control law employed a reduced HIV model, comprising two nested loops, a linearized feedback and a LQ regulator. It showed that it is not possible to completely eliminate the infection, but it can drive the virion particles to a number below the threshold specification (50 virus copies $/ \mathrm{mm}^{3}$ in plasma are undetectable in HIV patients). Also they showed that the controlled system is stable to moderate uncertainties in the HIV model parameters.

In this work a novel nonlinear PI-type controller is proposed in order to provide systematic drug-scheduling which drives the HIV virus concentration to minimal values in simulation tests. Unlike the previous therapies based on control algorithms, the proposed control strategy has the advantage of interrupting the drug dosing permanently. The proposed control law contains a class of continuous bounded functions, in order to compensate the dynamic behavior of the virion concentration in plasma and possible unknown disturbances onto the system. Numerical experiments show the successful performance of the proposed methodology as an idealized HIV therapy.

\section{Mathematical Model for HIV Infection}

The mathematical model to describe the dynamics of the $\mathrm{HIV}$ and $\mathrm{CD} 4^{+} \mathrm{T}$ cells during the primary infection stage was taken from [23]. The model is based on the mass balance in the blood plasma taking into account the concentrations for uninfected $\mathrm{CD} 4^{+} \mathrm{T}$ cells $\left(x_{1}\right)$, infected cells $\left(x_{2}\right)$, and virion particles in plasma $\left(x_{3}\right)$, all of them expressed in $\mathrm{mg} \mathrm{L}^{-1}$ as follows:

$$
\begin{aligned}
& \dot{x}_{1}=k_{1}-k_{2} x_{1}-k_{3} x_{1} x_{3}, \\
& \dot{x}_{2}=k_{3} x_{1} x_{3}-k_{4} x_{2}, \\
& \dot{x}_{3}=k_{5} x_{2}-k_{2} x_{3}+u(t)
\end{aligned}
$$

with $\mathbf{x}=\left[\begin{array}{lll}x_{1} & x_{2} & x_{3}\end{array}\right]$ as the state vector which belongs to a compact domain $\Omega \in \mathbb{R}_{+}^{3}$. The term $k_{3} x_{1} x_{3}$ corresponds to the rate of the infection of the $\mathrm{CD} 4^{+} \mathrm{T}$ cells by the virus and $k_{i} x_{2}$ is the rate of diminishment of infected cells. The parametric identification of this kind of systems is somewhat difficult, due to the quality of the available experimental data [24]; in particular, the measurements of the parameters and variables of the HIV medical tests depend, in some degree, on each commercial laboratory, such that each one has its own set of normal values and these values depend on the equipment or method used [25]. Generally the parameters for these models are reported in cell/microliter; however the drug administration is related with mass concentration units $\left(\mathrm{mg} \mathrm{L}^{-1}\right)$ [26]; therefore in order to be in agreement with the mass balances units, the following parameters are considered for this work: $k_{1}=50.0 \mathrm{mg} \mathrm{L}^{-1} \mathrm{~d}^{-1}, k_{2}=0.05 \mathrm{~d}^{-1}, k_{3}=$ $5 e-4 \mathrm{~L} \mathrm{mg}^{-1} \mathrm{~d}^{-1}, k_{4}=0.4 \mathrm{~d}^{-1}, k_{5}=40.0 \mathrm{~d}^{-1}$, and $k_{6}=$ $9.0 \mathrm{~d}^{-1}$; all of these kinetic constants are nonnegative and $k_{1}$ represents the constant rate of $\mathrm{CD}^{+} \mathrm{T}$ cell generation; $k_{2}$ is their death rate per capita. The term $u(t)$ is the exogenous control input given by the drug injection administration, under the assumption that the corresponding drug is able to eliminate the virion particles in plasma. From the above, the control input is imposed additively in the corresponding state equation.

\section{Control Design}

Let us consider a generalized space state representation of the system (1):

$$
\begin{aligned}
& \dot{\mathbf{x}}=f(\mathbf{x})+\varphi(t)+g(\mathbf{x}) \mathbf{u}(t), \\
& \mathbf{y}=h(\mathbf{x})=C \mathbf{x},
\end{aligned}
$$

where $\mathbf{x} \in \mathbb{R}_{+}^{n}$ is the corresponding state vector, $\mathbf{y} \in \mathbb{R}_{+}^{m}$ is the measured system output vector, with $m \leq n, f: \mathbb{R}^{n^{+}} \rightarrow$ $\mathbb{R}^{n}$ is a smooth vector field given by $f(\mathbf{x})=\left[k_{1}-k_{2} x_{1}-\right.$ $\left.k_{3} x_{1} x_{3} ; k_{3} x_{1} x_{3}-k_{4} x_{1} ; k_{5} x_{1}-k_{6} x_{3}\right]^{\mathrm{T}}, g(\mathbf{x})=\left[\begin{array}{lll}0 & 0 & 1\end{array}\right]^{\mathrm{T}}$, $C=\left[\begin{array}{lll}0 & 0 & 1\end{array}\right]^{\mathrm{T}}$ is the measurement coefficient matrix, $n=3$ is the order of the system (2), $m=1$ is the dimension of the measured vector for the specific case of study, and $\varphi(t)$ is an additive bounded disturbance.

Now, let us consider the following hypothesis:

(H1) The control input $\mathbf{u}(t)$ is bounded; that is, $(\|\mathbf{u}(t)\| \leq$ $\overline{\mathbf{u}})$.

(H2) $\|\varphi(t)\| \leq ð, f(\mathbf{x}) \in C^{\infty}$.

(H3) $\|f(\mathbf{x})\| \leq \mathscr{F},\|g(\mathbf{x})\| \leq G, \forall \mathbf{x} \in \mathbb{R}_{+}^{3}, F, G$, ð $<\infty$. 
Proposition 1. Consider the dynamical system (1) on the compact domain $\Omega \in \mathbb{R}_{+}^{3}$ and suppose that H1-H3 are satisfied, then the following feedback control input achieves the regularization of (1) at the desired reference value $x_{s p}$ :

$$
\begin{aligned}
\mathbf{u}(t)= & -g_{1} \frac{\mathbf{e}(t)}{1+|\mathbf{e}(t)|} \\
& -g_{2} \operatorname{sign}(\mathbf{e}(t)) \int_{0}^{t} \exp ^{-(\mathbf{e}(\sigma))^{2}} d \mathbf{e}(\sigma),
\end{aligned}
$$

where $\mathbf{e}(t)=C x-C x_{s p}$ is the regulation error, $x_{s p}$ is the desired set point and $g_{1}$ and $g_{2}$ are the named control's gains.

The proposed controller is inspired on the framework of the sliding-mode theory, which provides some robustness properties against external disturbances [27]; however and despite its robust performance, the employment of discontinuous controllers leads to an important closed-loop performance degradation due to the chattering phenomena. From the above, some alternative designs as the high order sliding-mode and sigmoid controllers have been designed in order to provide enough smoothness to the control action $[28,29]$.

Therefore, the proposed controller includes two bounded sigmoid functions as described by (4); the first term of the proposed methodology tries to compensate the nonlinear behavior of the system and the second one tries to compensate the additive disturbance. Note that the integral term is multiplied with the sign function in order to allow a sign change in this term and diminish the chattering from the standard sliding-mode controllers, smoothing the discontinuous nature of the sign function.

3.1. Sketch of Proof of Proposition 1. Consider the Lyapunov candidate function:

$$
\mho=\frac{1}{2} \mathrm{e}^{2}
$$

The time derivative along the trajectories of (5) is

$$
\dot{\mho}=\text { è. }
$$

Here is considered a regulation case, where the set point is constant; that is, $\dot{x}_{\text {sp }}=0$, in consequence $\dot{\mathbf{e}}=C \dot{x}$ and $\varphi(t)$.

Therefore,

$$
\dot{\mho}=\mathbf{e} C(f(\mathbf{x})+\varphi+g(\mathbf{x}) \mathbf{u}(t)) .
$$

Substituting the proposed feedback control input in (7),

$$
\begin{aligned}
\dot{\mho} & =\mathbf{e} C(f(\mathbf{x})+\boldsymbol{\varphi}+g(\mathbf{x}) \\
& \left.\cdot\left(-g_{1} \frac{\mathbf{e}}{1+|\mathbf{e}|}-g_{2} \operatorname{sign}(\mathbf{e}) \int_{0}^{t} \exp ^{-(\mathbf{e})^{2}} d \mathbf{e}(\sigma)\right)\right) .
\end{aligned}
$$

Now, considering that

$$
\begin{aligned}
\left\|\frac{\mathbf{e}}{1+|\mathbf{e}|}\right\| & \leq 1, \\
\left\|\operatorname{sign}(\mathbf{e}) \int_{0}^{t} \exp ^{-(\mathbf{e})^{2}} d \mathbf{e}(\sigma)\right\| & \leq 1 .
\end{aligned}
$$

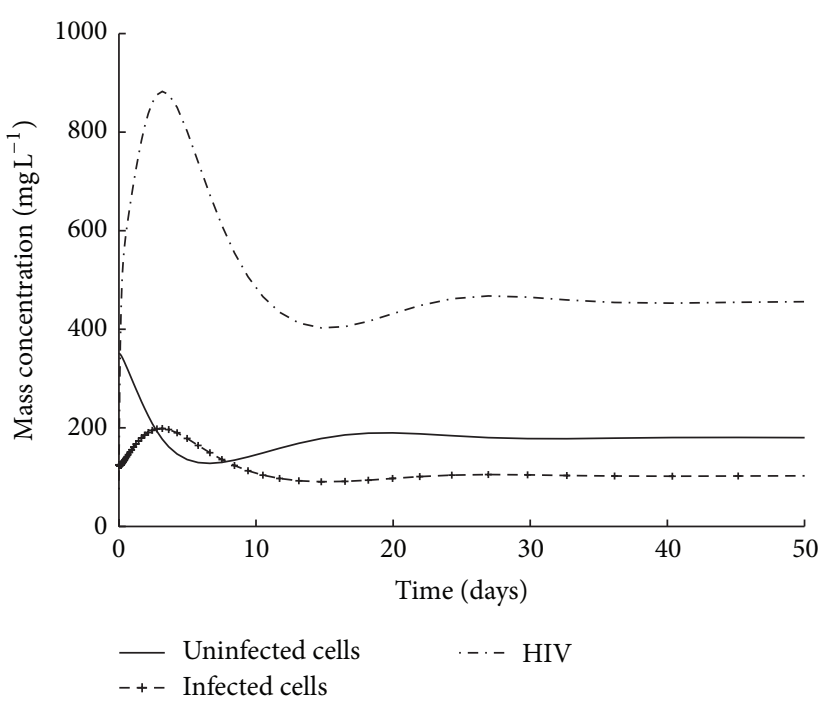

FIgURE 1: Open-loop behavior of the HIV dynamics.

The above, because the function $\mathbf{e} /(1+|\mathbf{e}|)$ is a class of sigmoid functions, $\operatorname{sign}(\mathbf{e})$ is the standard sign function and $\int_{0}^{t} \exp ^{-(\mathbf{e})^{2}} d \mathbf{e}(\sigma)$ is an erf-type (sigmoid) function.

Now, considering the hypotheses $(\mathrm{H} 1)$ to $(\mathrm{H} 3)$,

$$
\begin{aligned}
\dot{\boldsymbol{\mho}} & \leq \mathbf{e} C\left(\mathscr{F}+ð+G\left(-g_{1}\left\|\frac{\mathbf{e}}{1+|\mathbf{e}|}\right\|\right.\right. \\
& \left.\left.-g_{2}\|\operatorname{sign}(\mathbf{e})\|\left\|\int_{0}^{t} \exp ^{-(\mathbf{e})^{2}} d \mathbf{e}(\sigma)\right\|\right)\right) .
\end{aligned}
$$

Finally,

$$
\dot{\mho} \leq C\left(\mathscr{F}-g_{1} G+ð-g_{2} G\right)\|\mathbf{e}\| .
$$

If

$$
\begin{aligned}
g_{1} G & >F, \\
g_{1} & >G^{-1} F, \\
g_{2} G & >\partial, \\
g_{2} & >G^{-1} \partial,
\end{aligned}
$$

therefore,

$$
\dot{\mho} \leq 0
$$

Therefore, it can be concluded that the closed-loop system (2) is stable at $\mathbf{e}(t)=0$, such that $x=x_{\mathrm{sp}}$.

In particular, the integral term is considered to compensate the effect of the additive bounded disturbance $\varphi(t)$, as is showed in the stability analysis under the Lyapunov framework (see (11)).

\section{Results and Discussion}

Numerical experiments were done in order to show the open-loop and closed-loop behavior of the model for HIV 
infection. From the above, a PC computer with Intel Core i7 processor was used and the ordinary differential equations systems solver libraries, in particular, 23s ODE solver from MATLAB $^{\mathrm{Tm}}$, were employed. The system was simulated considering the following initial conditions: $x_{1,0}=350 \mathrm{mg} / \mathrm{L}$, $x_{2,0}=125 \mathrm{mg} / \mathrm{L}$, and $x_{3,0}=75 \mathrm{mg} / \mathrm{L}$; the disturbance considered in the virion particles in plasma is given by $\varphi(t)=$ $5 \sin (10 t)$. Firstly, Figure 1 shows the behavior of uncontrolled system, where an important increase for the HIV concentration compared to the initial condition can be observed, while the final mass concentration of the uninfected cells diminished to $180.5 \mathrm{mg} / \mathrm{L}$ and the final infected cell concentration is $102 \mathrm{mg} / \mathrm{L}$; these values provide an important evidence that the infection has not yet reached the AIDS stage. Figure 2 shows the corresponding 3D phase portrait, where the evolution of the trajectory described above is observed. The chemotherapy treatment via drug injection started at $t=75$ days; the treatment was conducted by the proposed controller; the parameters of the proposed controller are $g_{1}=1100 \mathrm{~d}^{-1}$ and $g_{2}=10 \mathrm{~d}^{-2}$. In Figure 3 an immediate response of the $\mathrm{HIV}$ concentration reaching the required set point $\left(x_{\mathrm{sp}}=\right.$ $0 \mathrm{mg} / \mathrm{L}$ ) in 15 days from the open-loop HIV concentration of $450 \mathrm{mg} / \mathrm{L}$ is observed. Besides, Figure 4 is related with the immediate response of the increase of the uninfected cell concentration (from $180.5 \mathrm{mg} / \mathrm{L}$ to $977 \mathrm{mg} / \mathrm{L}$ ) and the decrease of the infected cells (from $102.5 \mathrm{mg} / \mathrm{L}$ to $0 \mathrm{mg} / \mathrm{L}$ ); under this frame the corresponding closed-loop trajectory is presented in a 3D phase portrait (Figure 5). An important goal of the proposed methodology was the named control's effort; when the chemotherapy was started, the proposed methodology injected $1100 \mathrm{ng} / \mathrm{L}$ of the hypothetic drug; on the other hand, when the HIV concentration falls, the proposed methodology decreased the concentration of the injected drug to reach a null concentration. Therefore it is not necessary to maintain the drug application in order to keep the HIV concentration in a small enough value; this can be observed in Figure 6. For comparison purposes, a standard sliding-mode and hyperbolic tangent feedback [3032] are implemented; they are compared with the proposed methodology via performance index proposed in [33]. The performance index is related with the integral evolution of the average of the square of the regulation error; the methodology with the lower index is considered to be of the best performance. As observed in Figure 7 the methodology proposed in this work presents the better performance.

\section{Conclusions}

In this work an alternative therapy based on a nonlinear PI feedback control law to minimize the HIV concentration in blood plasma was presented. The proposed methodology contains a class of bounded functions in order to provide a satisfactory performance in the regulation of the number of virion particles and infected $\mathrm{CD} 4^{+} \mathrm{T}$ cells using a single input model with unknown disturbances. This approach shows by simulation an effective diminishment of the HIV concentration under the drug dosing scheme, which drives the cells near to health, improving the quality of life and

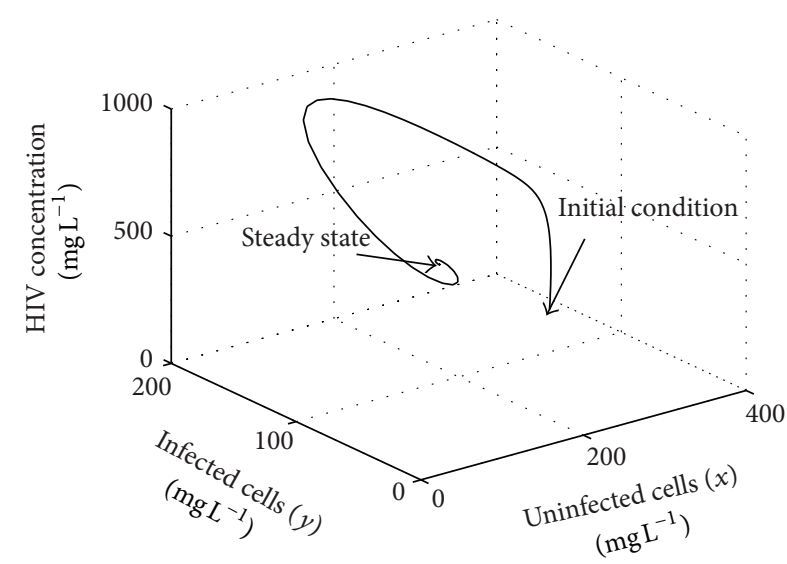

Figure 2: Phase portrait of the open-loop system.

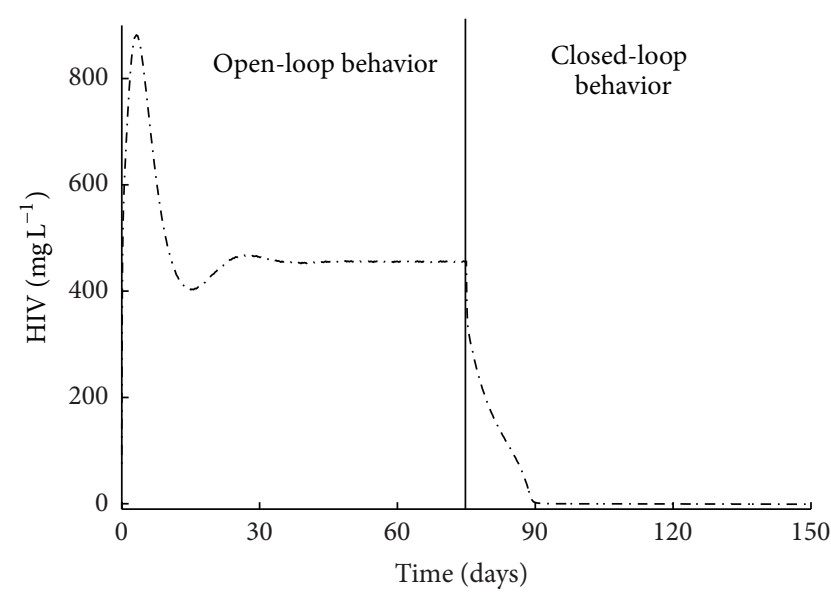

FIgURE 3: Closed-loop dynamics of the HIV concentration.

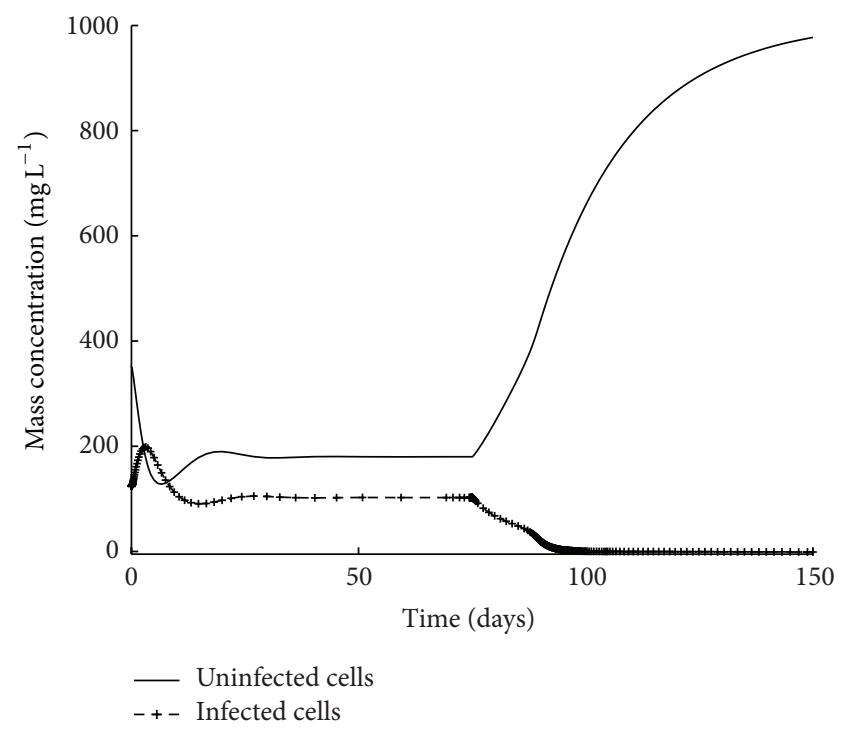

FIGURE 4: Closed-loop behavior of the uncontrolled concentrations. 


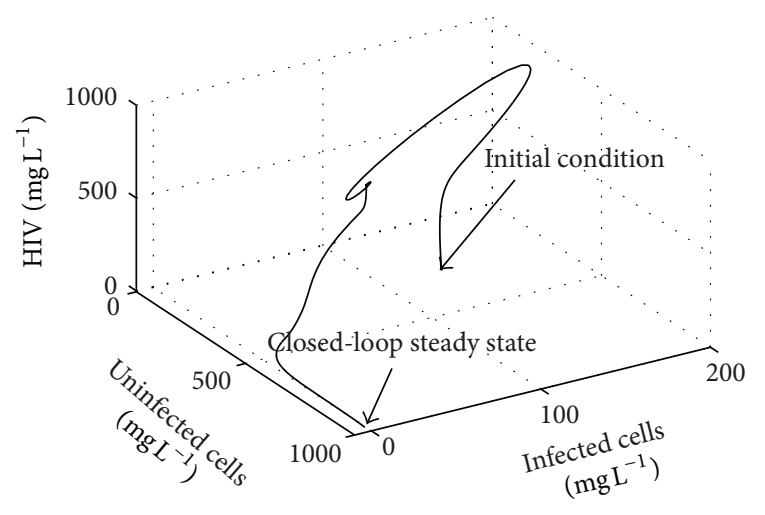

FIGURE 5: Closed-loop phase portrait of HIV dynamics.

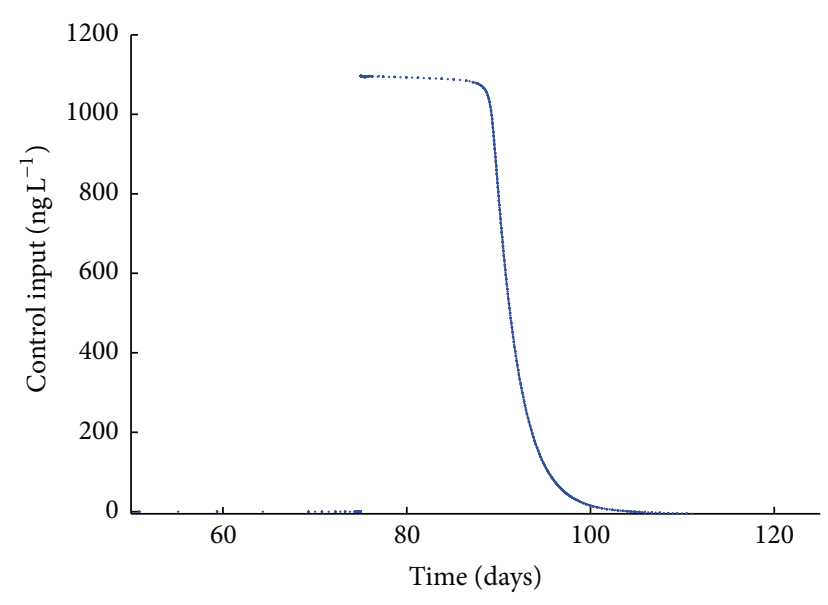

FIgURE 6: Control's effort for the proposed controller.

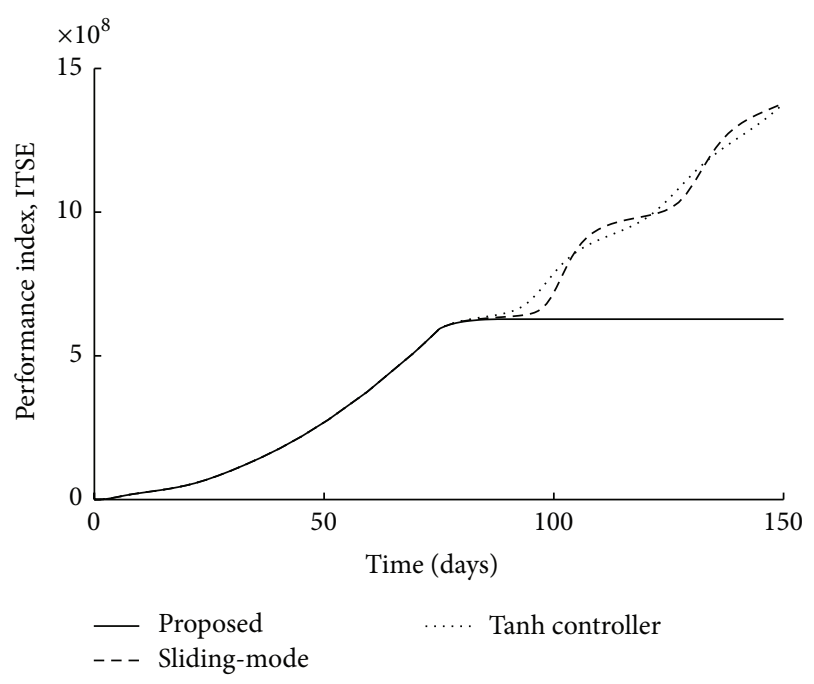

FIGURE 7: Performance index for the considered controllers.

longevity. Also this approach can avoid the drug resistance due to its minimal drug dosing values. Moreover, a better performance of the current methodology was achieved in contrast to other control laws.

\section{Competing Interests}

The authors have declared no competing interests.

\section{Acknowledgments}

Rigel Valentín Gómez-Acata wishes to acknowledge the CINVESTAV and the CONACyT for their support.

\section{References}

[1] M. S. Cohen, Y. Q. Chen, M. McCauley et al., "Prevention of HIV-1 infection with early antiretroviral therapy," The New England Journal of Medicine, vol. 365, no. 6, pp. 493-505, 2011.

[2] A. Anglemyer, T. Horvath, and G. Rutherford, "Antiretroviral therapy for prevention of HIV transmission in HIV-discordant couples," The Journal of the American Medical Association, vol. 310, no. 15, pp. 1619-1620, 2013.

[3] H. Wu, E. Connick, D. R. Kuritzkes et al., "Multiple CD4+ cell kinetic patterns and their relationships with baseline factors and virological responses in HIV type 1 patients receiving highly active antiretroviral therapy," AIDS Research and Human Retroviruses, vol. 17, no. 13, pp. 1231-1240, 2001.

[4] E. Fanales-Belasio, M. Raimondo, B. Suligoi, and S. Buttò, "HIV virology and pathogenetic mechanisms of infection: a brief overview," Annali Dell'Istituto Superiore Di Sanita, vol. 46, no. 1, pp. 5-14, 2010.

[5] W. C. Greene, Z. Debyser, Y. Ikeda et al., "Novel targets for HIV therapy," Antiviral Research, vol. 80, no. 3, pp. 251-265, 2008.

[6] A. M. Elaiw, "Global properties of a class of HIV models," Nonlinear Analysis-Real World Applications, vol. 11, no. 4, pp. 2253-2263, 2010.

[7] Y. X. Huang, S. L. Rosenkranz, and H. L. Wu, "Modeling HIV dynamics and antiviral response with consideration of timevarying drug exposures, adherence and phenotypic sensitivity," Mathematical Biosciences, vol. 184, no. 2, pp. 165-186, 2003.

[8] L. Shen, S. A. Rabi, A. R. Sedaghat et al., "A critical subset model provides a conceptual basis for the high antiviral activity of major HIV drugs," Science Translational Medicine, vol. 3, no. 91, Article ID 91ra63, 2011.

[9] H. Chang and A. Astolfi, "Enhancement of the immune system in HIV dynamics by output feedback," Automatica, vol. 45, no. 7, pp. 1765-1770, 2009.

[10] H. Shim, N. H. Jo, H. Chang, and J. H. Seo, "A system theoretic study on a treatment of AIDS patient by achieving long-term non-progressor," Automatica, vol. 45, no. 3, pp. 611-622, 2009.

[11] I. Cremin, R. Alsallaq, M. Dybul, P. Piot, G. Garnett, and T. B. Hallett, "The new role of antiretrovirals in combination HIV prevention: a mathematical modelling analysis," AIDS, vol. 27, no. 3, pp. 447-458, 2013.

[12] M. E. Brandt and G. Chen, "Feedback control of a biodynamical model of HIV-1," IEEE Transactions on Biomedical Engineering, vol. 48, no. 7, pp. 754-759, 2001.

[13] S. S. Ge, Z. Tian, and T. H. Lee, "Nonlinear control of a dynamic model of HIV-1," IEEE Transactions on Biomedical Engineering, vol. 52, no. 3, pp. 353-361, 2005.

[14] J. H. Ko, W. H. Kim, and C. C. Chung, "Optimized structured treatment interruption for HIV therapy and its performance analysis on controllability," IEEE Transactions on Biomedical Engineering, vol. 53, no. 3, pp. 380-386, 2006. 
[15] R. Zurakowski and A. R. Teel, "A model predictive control based scheduling method for HIV therapy," Journal of Theoretical Biology, vol. 238, no. 2, pp. 368-382, 2006.

[16] V. Radisavljevic-Gajic, "Optimal control of HIV-virus dynamics," Annals of Biomedical Engineering, vol. 37, no. 6, pp. 12511261, 2009.

[17] G. Pannocchia, M. Laurino, and A. Landi, "A model predictive control strategy toward optimal structured treatment interruptions in anti-HIV therapy," IEEE Transactions on Biomedical Engineering, vol. 57, no. 5, pp. 1040-1050, 2010.

[18] H. Zarei, A. V. Kamyad, and M. H. Farahi, "Optimal control of HIV dynamic using embedding method," Computational and Mathematical Methods in Medicine, vol. 2011, Article ID 674318, 9 pages, 2011.

[19] D. Thakur and B. Marchand, "Hybrid optimal control for HIV multi-drug therapies: a finite set control transcription approach," Mathematical Biosciences and Engineering, vol. 9, no. 4, pp. 899-914, 2012.

[20] H. Zarei, A. V. Kamyad, and A. A. Heydari, "Fuzzy modeling and control of HIV infection," Computational and Mathematical Methods in Medicine, vol. 2012, Article ID 893474, 17 pages, 2012.

[21] W. Kim, H. B. Chung, and C. C. Chung, "Constant drug dose in human immuno-deficiency virus-infected patients to induce long-term non-progressor status: bifurcation and controllability approach," IET Systems Biology, vol. 7, no. 3, pp. 79-88, 2013.

[22] M. Barão and J. M. Lemos, "Nonlinear control of HIV-1 infection with a singular perturbation model," Biomedical Signal Processing and Control, vol. 2, no. 3, pp. 248-257, 2007.

[23] H. C. Tuckwell and F. Y. M. Wan, "On the behavior of solutions in viral dynamical models," BioSystems, vol. 73, no. 3, pp. 157$161,2004$.

[24] M. Laurino, A. Landi, and G. Pannocchia, "Parameters identification of HIV dynamic models for HAART treated patients: a comparative study," in Proceedings of the American Control Conference (ACC '14), pp. 2759-2764, Portland, Ore, USA, June 2014.

[25] Normal Laboratory Values, "Fact Sheet Number 120A," http://www.aidsinfonet.org/uploaded/factsheets.

[26] R. S. Autar, F. W. N. M. Wit, J. Sankote et al., "Nevirapine plasma concentrations and concomitant use of rifampin in patients coinfected with HIV-1 and tuberculosis," Antiviral Therapy, vol. 10, no. 8, pp. 937-943, 2005.

[27] C. Edwards and S. K. Spurgeron, Sliding Mode Control: Theory and Applications, Taylor \& Francis, London, UK, 1998.

[28] S. V. Emelyanov, S. K. Korovin, and A. Levant, "Higher-order sliding modes in control systems," Differential Equations, vol. 29, no. 11, pp. 1627-1647, 1993.

[29] A. Ateş, B. B. Alagöz, C. Yeroğlu, and H. Alisoy, "Sigmoid based PID controller implementation for rotor control," in Proceedings of the European Control Conference (ECC '15), pp. 458-463, IEEE, Linz, Austria, July 2015.

[30] S. Drakunov and V. Utkin, "Sliding mode observers. Tutorial," in Proceedings of the 34th IEEE Conference on Control and Decision, pp. 3376-3378, New Orleans, La, USA, December 1995.

[31] C. Edwards, S. Spurgeon, C. Tan, and N. Patel, "Sliding-mode observers," in Mathematical Methods for Robust and Nonlinear Control: EPSRC Summer School, M. Turner and D. Bates, Eds., vol. 367 of Lecture Notes in Control and Information Sciences, pp. 221-242, Springer, London, UK, 2007.
[32] L. Fridman, J. Moreno, and R. Iriarte, Sliding Modes after the First Decade of the 21st Century: State of the Art, Springer, Berlin, Germany, 2011.

[33] B. A. Ogunnaike and W. H. Ray, Process Dynamics, Modeling, and Control, Oxford University Press, New York, NY, USA, 1994. 


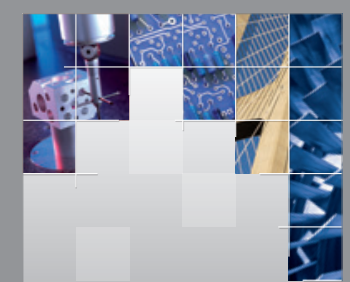

\section{Enfincering}
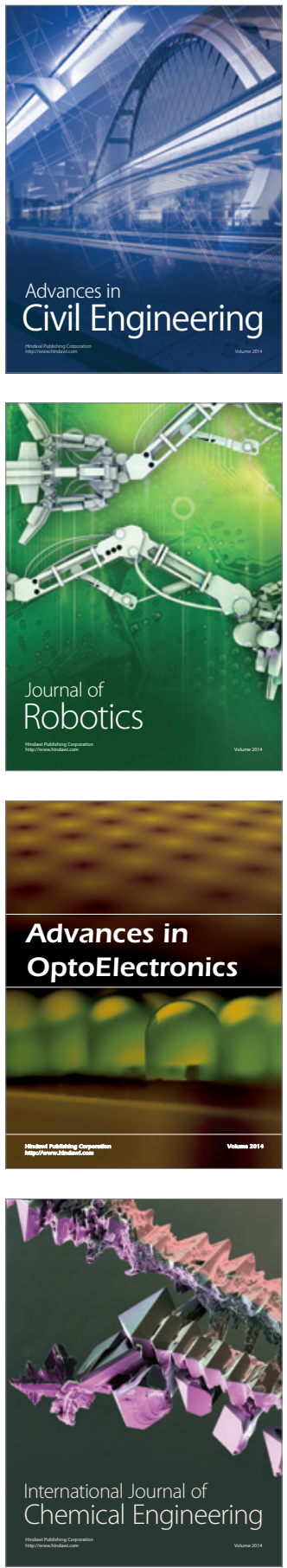

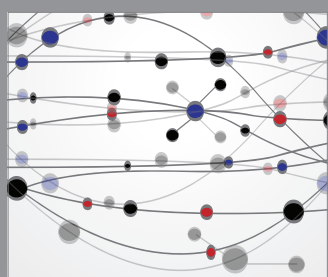

The Scientific World Journal

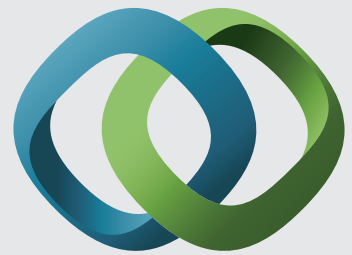

\section{Hindawi}

Submit your manuscripts at

http://www.hindawi.com
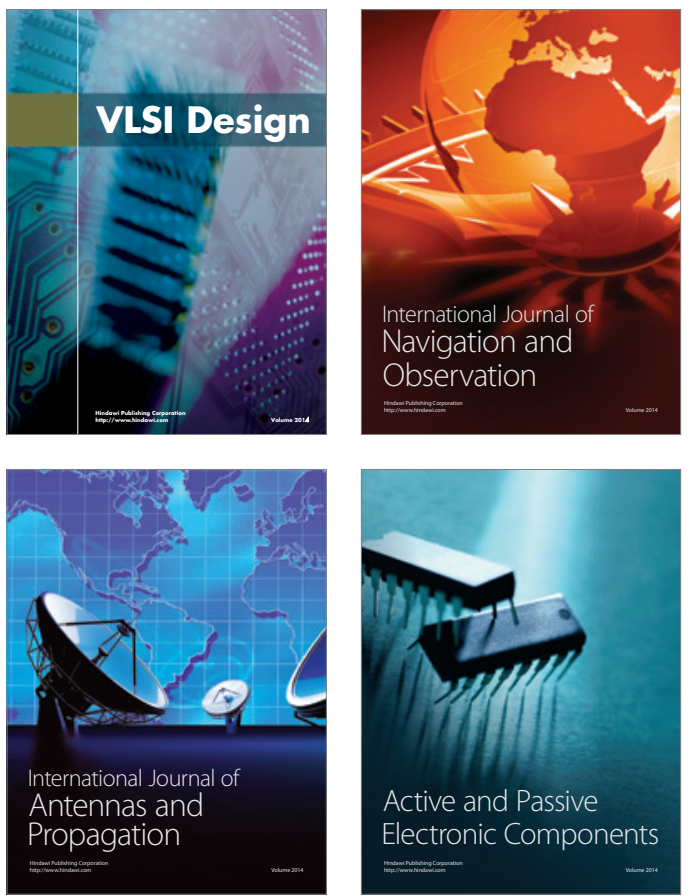
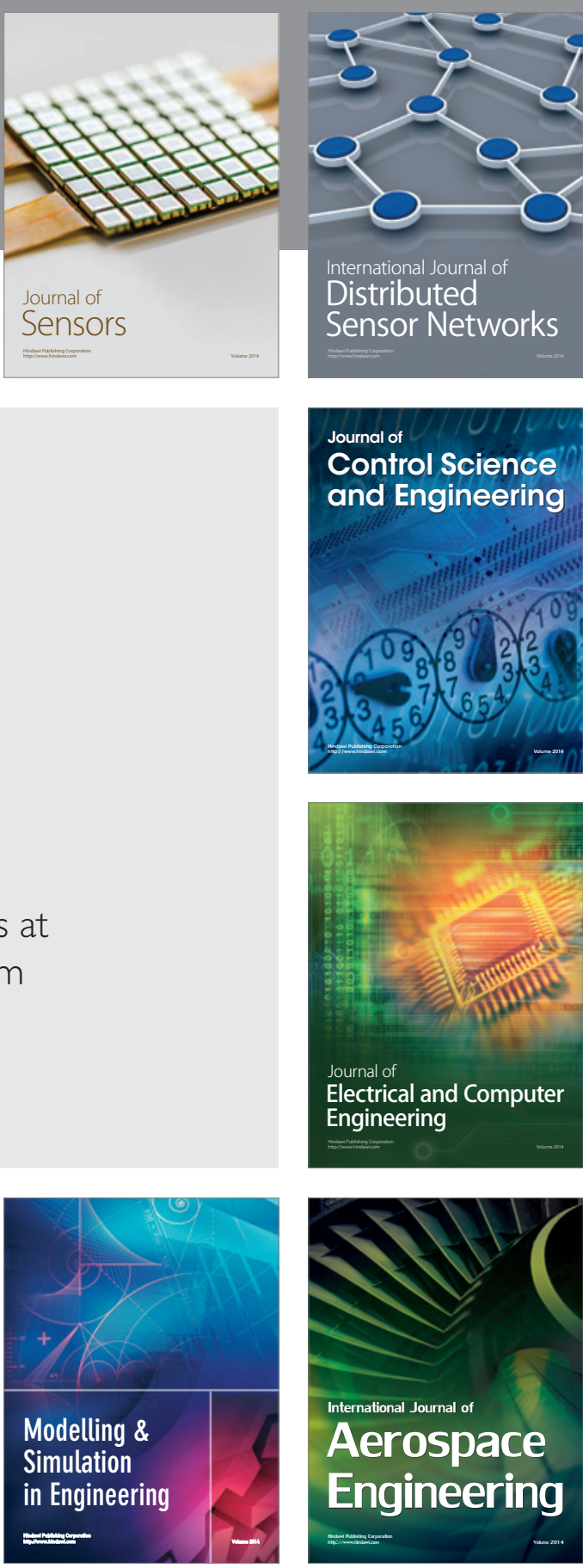

International Journal of

Distributed

Sensor Networks

Journal of

Control Science

and Engineering
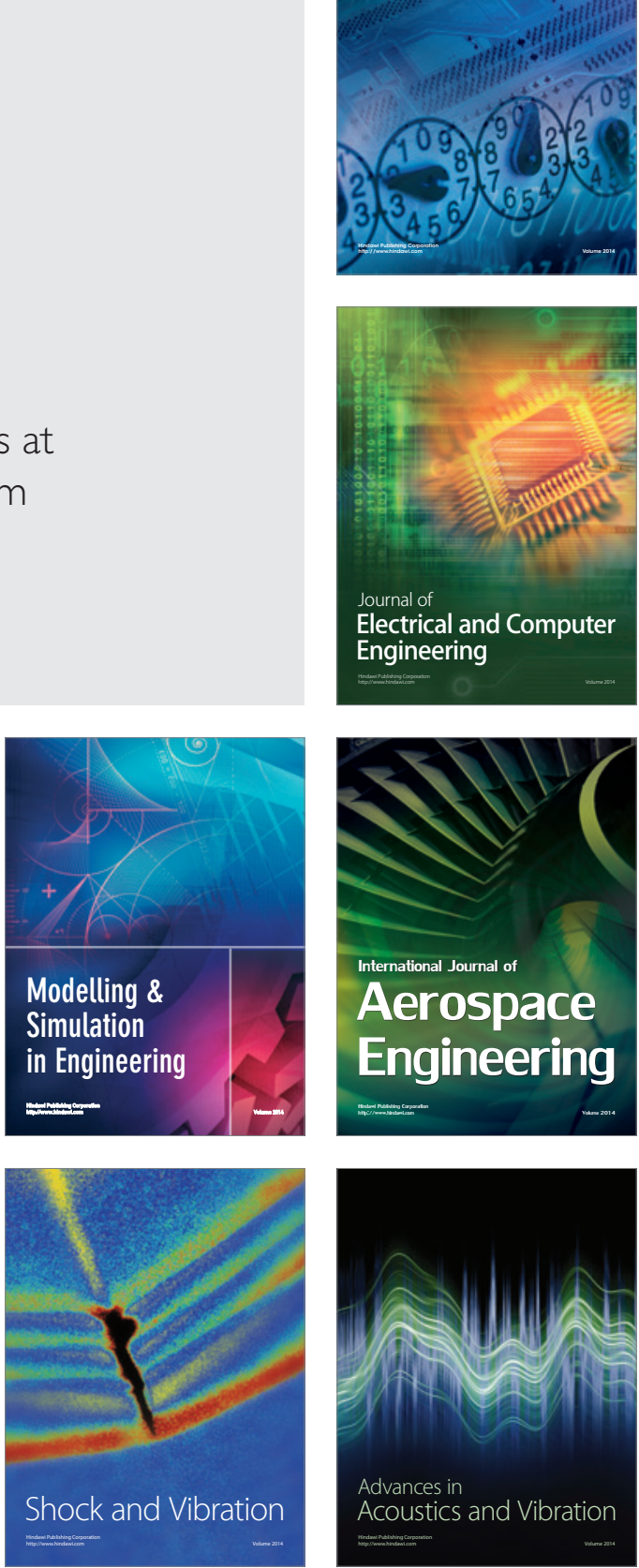